УДК [069.12:78](470.41)

DOI 10.37972/chgpu.2020.99.85.024

Г. Р. Камалова

\title{
ПРИМЕНЕНИЕ РЕКРЕАЦИОННО-ОЗДОРОВИТЕЛЬНЫХ ПРАКТИК В ПРОЦЕССЕ КУЛЬТУРНО-ДОСУГОВОЙ ДЕЯТЕЛЬНОСТИ
}

\author{
Казанский государственный институт культуры, г. Казань, Россия
}

\begin{abstract}
Аннотация. В рамках реализации музыкально-образовательных программ (лекториев) в музеях и галереях г. Казани с целью развития музыкально-эстетической культуры личности на основе общепринятого мнения о целительном свойстве искусства автором статьи были разработаны и внедрены рекреационно-оздоровительные практики, способствующие удовлетворению интересов и потребностей посетителей. Анализ методической литературы в области культурнодосуговой деятельности, музыкального искусства выявил наиболее успешные формы, методы, приемы, способствующие достижению цели работы. Обзор российского и зарубежного опыта по исследуемой теме способствовал определению музея как культурно-досугового учреждения, обладающего наибольшими возможностями в реализации рекреационно-оздоровительных практик с разными возрастными группами. Материалы исследования могут быть широко использованы педагогическими работниками, методистами, студентами учреждений, реализующих образовательные программы в социально-культурной и культурно-досуговой сфере, по музыкальному искусству, медицине.
\end{abstract}

Ключевые слова: арт-терапевтические практики, музейное пространство, культурнодосуговая деятельность, музькотерапия, психоневрологические расстройства.

G. R. Kamalova

\section{RECREATIONAL AND HEALTH-IMPROVING PRACTICES IN CULTURE-LEISURE ACTIVITY}

\section{Kazan State Institute of Culture, Kazan, Russia}

\begin{abstract}
While implementing musical-educational programs (lecture courses) in museums and galleries of Kazan, the author elaborated and introduced recreational and health-improving practices promoting satisfaction of the interests and needs of the public. The programs were implemented with a view of developing musical-esthetic culture of a personality and based on the conception of the healing properties of art. The analysis of methodological literature in the sphere of cultural-leisure activity and musical art revealed the most efficient forms, methods and techniques, enabling to achieve the work objective. The review of foreign practices in the researched sphere contributed to defining a museum as a culturalleisure establishment characterised by opportunities for implementation of recreational and healthimproving practices at various age groups. The research materials can be of interest for educators, methodologists, and students of educational establishments providing programs in social and cultural, cultural and leisure, musical art, and medicine spferes.
\end{abstract}

Keywords: art therapy practices, museum space, culture and leisure activity, music therapy, psychoneurological disorders.

Актуальность исследуемой проблемы. Потенциал рекреационно-оздоровительного направления культурно-досуговых учреждений, использование средств искусства в оздоровительных целях являются актуальными вопросами, требующими внимания со стороны государства. В настоящее время в Российской Федерации активно раз- 
виваются оздоровительные культурно-досуговые программы для детей и подростков, что подтверждается указом Президента от 29.05.2017 № 240 «Об объявлении в Российской Федерации „Десятилетия детства"», в котором одной из ключевых позиций является внедрение механизмов поддержки проектов государственно-частного партнерства в сфере организации отдыха и оздоровления детей [8]. Развитие этих программ опирается на одну из главных функций культурно-досуговой деятельности - гедонистическую, которая в современном обществе становится одной из ведущих «...и сегодня сменяет просветительскую модель деятельности культурно-досуговых учреждений на гедонистическую концепцию, согласно которой культура должна доставлять удовольствие, развлекать, успокаивать...» [2, с. 7]. Для нас актуально применение многофункциональных приемов и методов, способствующих не только реализации рекреационно-оздоровительного направления культурно-досуговой деятельности, но и развитию с опорой на средства элитарного музыкального искусства музыкально-эстетической культуры, необходимой для гармоничного развития личности в целом. Цель статьи - практически обосновать актуальность применения рекреационно-оздоровительных практик в процессе культурнодосуговой деятельности.

Материал и методика исследований. Проведен анализ методической литературы в области культурно-досуговой деятельности, музыкального искусства; выделены следующие виды рекреационно-оздоровительных практик в процессе культурно-досуговой деятельности в музейном пространстве: метод театральной деятельности как средство вовлечения детей и подростков в активную творческую деятельность, а также как вспомогательное средство коррекции синдрома дефицита внимания и гиперактивности (далее СДВГ); приемы импрессивного и экспрессивного метода музыкотерапии: творческая медитация, музицирование на фортепиано, актуальные для лиц разного возраста и способствующие активному развитию музыкально-эстетической культуры (процесс освоения техники игры на инструменте основан на приемах, способствующих снятию стресса, напряжения, выходу негативных эмоций)

Для выявления интересов и потребностей лиц $18+$ в применении рекреационнооздоровительных практик в музыкально-образовательных программах музеев и галерей г. Казани применялся метод анкетирования.

Результаты исследований и их обсуждение. Рекреационно-оздоровительное направление в сфере досуга подразумевает организацию деятельности, осуществляемой в свободное от учебы/работы время, способствующей полноценному отдыху человека, восстановлению его духовных и физических сил. Досуговые рекреационнооздоровительные мероприятия, опирающиеся на знания и достижения из психологии, биологии, медицины, физиологии, способствуют снятию напряжения и усталости, уменьшению влияния стресса, связанного с рабоотой и межличностным общением, поддержанию и восстановлению физического здоровья и т. д. [3].

Необходимо отметить, что участие в рекреационно-оздоровительных мероприятиях помогает развитию коммуникативных, мотивационных, дисциплинарных, творческих навыков личности. Таким образом, рекреационно-оздоровительное направление в культурно-досуговой деятельности обладает не только восстановительным, оздоровительным потенциалом, но и культурно-развивающим, необходимым для гармонично развитой личности.

Рассматривая потенциал музыкального искусства в применении рекреационнооздоровительных практик, мы опирались на позиции ученых-практиков, доказавших целительное свойство музыки. Так, установлено, что человеческий организм резонирует на музыку подобно струне, так как подчинен биоритмам; поэтому, используя музыку в качестве раздражителя, можно усилить ритмические процессы организма $[9$, с. 183]. В работе 
С. В. Барановой отмечается, что человеческий мозг воспринимает музыку одновременно обоими полушариями: левое обрабатывает ритм, правое - мелодию и тембр. Самое сильное воздействие на организм человека оказывает ритм. Ритмы музыкальных произведений находятся в диапазоне от 2,2 до 4 колебаний в секунду, что очень близко к частоте дыхания и сердцебиения [1]. По мнению В. И. Петрушина, музыкальные произведения легких жанров, в основу которых положен ритм, воспринимаются легче и пользуются большей популярностью, чем музыкальные произведения, относимые к серьезным жанрам [4, с. 174]. Таким образом, при выборе средств музыкального искусства - репертуара необходимо сделать акцент на главных составляющих музыки, которые оказывают эмоциональное воздействие на человека, - характер, жанр музыкального произведения и его ритмические характеристики.

По мнению Э. Иоаннидис, музейное пространство, состоящее из произведений искусств, в отличие от медицинских и социальных учреждений, способствует формированию гостеприимной и дружественной среды, которая может привести к вдохновению, при этом творческий процесс, связанный с созданием предметов искусства, является целительным [12].

В настоящее время многие музеи мира активно разрабатывают и применяют оздоровительные программы.

Национальная галерея Австралии разработала программы арт-терапии, охватывающие разные возрастные группы и учитывающие их потребности:

1. «Творческая медитация» (для детей 5-7 и 8-12 лет).

Участники с помощью помощника (учителя-фасилитатора) по медитации исследуют и размышляют над произведениями искусства, учатся понимать свои эмоции, делятся своим опытом.

2. «Йога на обед» для детей и взрослых.

Данная регулярная программа галереи позволяет посетителям сочетать занятия искусством и йогой в неформальной, расслабляющей обстановке [12].

Художественная галерея Гамильтона (Канада) подготовила индивидуальные туры для пожилых людей с афазией (расстройством языка, вызванным повреждением мозга, которое часто возникает после инсульта) с обязательным включением программы по приобретению художественного опыта создания предметов искусства. Лица, страдающие афазией, обладают полным интеллектом, но это состояние вызывает трудности как в понимании, так и в общении. Это часто вызывает чувство изоляции. Для решения проблемы общения с членами группы организаторами использовались жесты, флэш-карты [12].

Художественная галерея Новой Шотландии и общество Альцгеймера Новой Шотландии (Канада) объединились для того, чтобы создать захватывающую художественную программу для людей с деменцией и их опекунов. Участникам предлагается приобрести практический опыт работы в студии и получить возможность увидеть оригинальные произведения искусства в галерее. Программа разработана в сотрудничестве с персоналом музея, сотрудниками общества Альцгеймера и волонтерами для наилучшего обеспечения и удовлетворения потребностей целевой аудитории. В галерее реализуется также программа для детей с аутизмом: субботние художественные классы и ежегодная выставка как результат, здесь обеспечивают безопасную и благоприятную среду, где все участники могут выразить себя творчески. В работе участвуют художник и координатор по поддержке лиц с аутизмом, который продумывают художественную программу, включающую знакомство с произведениями искусства [12].

Изучив зарубежный и российский опыт, можем отметить, что музейное пространство является площадкой, реализующей профилактические и оздоровительные программы, направленные на снятие стресса, облегчение болей у взрослых и детей, повышение 
резервных способностей организма человека, лечение психосоматических заболеваний, психоневрологических расстройств, оздоровление имеющих физические нарушения пациентов реабилитационных центров и т. д. Заметим таюже, что «одна из самых прекрасных вещей в искусстве - это не только цвет, который мы видим на холсте, но и глубокий уровень эмоциональной связи и ощущений, которые он вызывает» [12]. Художественные музеи предоставляют пространство, где люди могут собраться, чтобы вдохновиться искусством и творчеством.

Разработка рекреационно-оздоровительных практик в сфере искусства для детей и подростков, по нашему мнению, подразумевает их вовлечение в творческий процесс, целительное свойство которого общеизвестно и доказано в трудах Н. И. Ереминой, В. И. Петрушина, А. В. Тороповой, Г. А. Прасловой, С. В. Шушарджана, Р. С. Шушарджана, Ю. Б. Некрасовой и др.

Одним из основных компонентов творчества является воображение, которое невозможно без мотивации, то есть желания сделать что-то новое, необычное, а также силы воли, настойчивости, необходимой во многих испытаниях и проверках. По мнению А. Беджан, творчество - это измерение, которое невозможно получить с помощью конкретных целей, во время отдельных уроков. Его необходимо описывать в более широком временном выражении. Речь идет о тех чертах творчества или воображения, которые описаны в большей степени в области психологии. Ученый выделяет такие черты творчества, как беглость воображения - возможность за короткое время представить большое количество образов, идей, ситуаций; пластичность, то есть легкость изменения точки зрения, иной способ подхода к проблеме, когда процесс оказывается неработоспособным; оригинальность - выражение новизны, новаторства. Далее А. Беджан в качестве эффективного метода рекомендует использовать метод театральной деятельности, который способствует развитию вышеописанных компонентов творчества [11].

Этот метод мы применяли в работе с детьми и подростками одной из СОШ г. Казани (10 человек), посещающими музыкально-образовательные программы (лектории) автора, а также с учащимися средней специальной музыкальной школы при Казанской государственной консерватории им. Н. Г. Жиганова, которые участвовали в лекториях и проявили желание дополнительно заниматься театральной деятельностью (6 человек). Площадкой для реализации данной программы являлась Детская студия-галерея им. И. К. Зарипова, с которой на протяжении долгого времени осуществляется сотрудничество в форме проведения концертов учащихся класса Г. Р. Камаловой, участия в городских мероприятиях, посвященных «Дню города», «Дню защиты детей»), «Дню музеев» и т. п. Особенность указанного учреждения заключается в популяризации творчества подрастающего поколения в виде часто сменяющихся выставок художественных работ детей и подростков. Открытие выставок, презентации мероприятий сопровождаются музыкальными номерами учащихся класса автора.

Целью организации подобной деятельности является вовлечение подростков-немузыкантов в активную творческую среду с помощью использования ведущего принципа работы - сотворчества, в котором участвуют еще и преподаватели, родители, сотрудники галереи.

Ярким примером применения принципа сотворчества является опыт Института современного искусства в г. Бостоне (США), в котором существует совет по искусству для подростков, планирующий для них события, такие как ежегодные национальные конференции для подростков и преподавателей в области искусства, на которых совместно обсуждаются проблемы и возможности, стоящие перед современным художественным образованием [13] 
Наша работа подразумевала организацию занятий по подготовке театральносказочных представлений в рамках музыкально-образовательных программ (лекториев) в музеях, галереях г. Казани. Она включала следующие этапы: разработка сценария на основе произведений художественной, музыкальной литературы; распределение ролей и отработка партий, работа над сценическим словом; краткое обучение детей и подростков - немузыкантов - музыкальной грамоте (авторский прием изучения нот по руке, объяснение ритмических основ музыки и т. д.) для совместного исполнения номеров с подростками-музыкантами на элементарных шумовых (самодельные маракасы), ударных (ксилофон), духовых инструментах (окарины, дудочки, флейта пана), что помогает через собственную игру получить максимальное удовольствие от общения с музыкой [5]; подготовка костюмов с привлечением родителей.

Необходимо отметить, что сотрудничество оказывает благотворное влияние на развитие творческих способностей ребенка. Так, по мнению А. Беджан, дети с раннего детства непрерывно творят посредством своих форм деятельности: игры, рисования, танца, песни и т. п. Однако взрослые имеют тенденцию блокировать их творчество с самого начала, то есть они ограничивают их в своей деятельности окриками, например: «Не шуми, у меня болит голова!», «Не бери, а то сломаешь что-нибудь!» и пр. Это лишь несколько типичных ситуаций блокировок в детском творчестве. Далее, как считает А. Беджан, возникает парадокс: ребенок вначале создает, потому что это его природа, взрослый подавляет эту тенденцию, а затем, к примеру, в рамках творческого образовательного процесca, он формирует и развивает его творчество, другими словами, заставляет ребенка заново открыть свою творческую природу и быть раскованным [11]. Мы считаем, что наилучший способ избежать данной проблемы - это осуществлять совместную деятельность детей и их родителей.

Опираясь на специфику театральной деятельности, являющейся синтезом музыки, сценической речи, сценического движения (танца), сценического действия, предположим, что данный метод эффективен в работе с таким распространенным недугом, оказывающим негативно влияние на процесс обучения детей и подростков, как синдром дефицита внимания и гиперактивности (СДВГ). Это психомоторное расстройство, признаками которого являются нарушение внимания, гиперактивность, импульсивность, выражающаяся в отсутствии самоконтроля, в резкой смене настроения. Нейропсихологическая коррекция детей с СДВГ, как правило, состоит из физических упражнений (растяжки), дыхательной гимнастики, глазодвигательных упражнений, упражнений для языка и мышц челюсти, упражнений для развития мелкой моторики рук, упражнений для релаксации и визуализации, функциональных упражнений, упражнений для развития коммуникативной и когнитивной сферы, упражнений с правилами [6]. Актуальность применения метода театральной деятельности обусловлена включением практически всех видов нейропсихологической коррекции. У одного ребенка (4 класс) из числа участников кружка проявлялись признаки данного синдрома. В процессе активного вовлечения в работу по созданию сценария, отработке роли, выучиванию музыкального материала появилась положительная динамика в организации рабочего процесса (увеличение концентрации внимания). Положительные изменения ученика автор связывает с использованием рекомендации профессора С. В. Шушарджана по проведению музыкально-педагогической технологии музыкотерапии, согласно которой упражнения, требующие усидчивости и концентрации внимания (в нашем случае это работа над музыкальными номерами), необходимо чередовать с активной деятельностью (проведение «физкультминуток» в галерее под аккомпанемент фортепиано) [10]. Благотворное воздействие оказывает также вовлечение ребенка, имеющего психоневрологические проблемы, в коллективную работу, которая формирует культуру поведения, общения со сверстниками и взрослыми. 
Таким образом, можно утверждать, что метод театральной деятельности в работе с детьми и подростками хорошо зарекомендовал себя не только в развитии творческих качеств личности, но и как рекреационно-оздоровительная практика, благотворно влияющая на ребенка, имеющего психоэмоциональное расстройство, например, СДВГ.

Успехом в применении метода театральной деятельности увенчалось выступление в новогоднем лектории, проводимом в форме театрально-сказочного представления «Кыш Бабай и его друзья» в Детской студии-галерее им. И. К. Зарипова, а также в 3-м лечебном корпусе Детской республиканской клинической больницы г. Казани. Ребята активно контактировали с публикой, загадывали загадки, а также исполняли танцевальные мелодии, песни разных стран и народов.

В массовых мероприятиях с детьми и подростками, посещающими музыкальнообразовательный лекторий в галереях, музеях г. Казани, применялся импрессивный метод музыкотерапии в форме творческой медитации по аналогии с работой, проводимой в Национальной галерее Австралии. Подразумевалось прослушивание в середине мероприятия музыкальных произведений, направленных на снятие напряжения, усталости, а также на проявление творчества в виде зарисовок образов, впечатлений, вызванных музыкальным произведением. Например, ученица 6 класса СОШ № 146 после прослушивания номеров «Аквариум» и «Лебедь» из цикла «Карнавал животных» К. Сен-Санса доработала эскиз в картину (с использованием дополнительных материалов: ваты для украшения лебедя, красок для изображения подводного мира), в которой оба номера сочетались в одном полотне. Данная работа получила теплый отклик публики на выставке в Детской картинной галерее им. И. К. Зарипова. В настоящее время, в связи с накоплением подобных картин, предполагается организация выставки.

В лектории, посвященном композиторам Республики Татарстан, были исполнены три музыкальные пьесы-притчи, написанные под впечатлением детских стихов «Мамочка, я увидел щенка», «Черепаха», «Гусь» Р. Миннулина. Композитор А. Сунгатуллина, рассказывая о своих произведениях, попросила публику прослушать их в расслабленном состоянии, с закрытыми глазами, для полноценного погружения в мир каждого из них. По окончании мероприятия аудитории предлагалось изобразить представленные образы, а также сравнить литературную (стихи Р. Миннулина) и музыкальную (пьесы-притчи А. Сунгатуллиной) версии. Публике предоставлялись листы бумаги, карандаши, ручки. Многие ребята, посещающие лекторий, просили разрешить взять эскизы домой, чтобы доделать работу. Мы считаем, что ценность данного приема заключается в получении новых впечатлений, вдохновения в процессе прослушивания музыки. Кроме того, использование данного приема между рубриками лекториев, которые включают в себя музыкальнопросветительское, гражданско-патриотическое, музыкально-образовательное направления, позволяет осуществить принцип чередования активной деятельности с отдыхом.

Музыкально-образовательные программы (лектории) в музеях и галереях г. Казани - это открытые мероприятия не только для детей и подростков, но и для всех желающих. Цель организации данных циклов - привлечь публику к активным творческим практикам. После проведения четырех мероприятий мы обратили внимание, что, помимо детей и подростков, эти мероприятия посещают люди и других возрастов (молодежь (студенты), взрослые, пожилые (60+)). С целью определения актуальности применения рекреационно-оздоровительных практик для разных возрастных категорий мы провели анкетирование. В таблице 1 приведены вопросы анкеты и полученные на них ответы.

На основе приведенных результатов мы пришли к выводу о том, что во всех группах есть потенциал к активным формам музыкального творчества. Выбор формы, а также цели творчества соответствуют возрасту. 
Потенциал к активным формам музыкально-эстетического творчества

\begin{tabular}{|c|c|c|c|}
\hline Вопросы & Группа лиц 18-32 лет & Группа лиц 36-55 лет & Группа лищ «60+» \\
\hline $\begin{array}{l}\text { Хотели бы Вы начать } \\
\text { заниматься музькой? }\end{array}$ & $\begin{array}{l}63,6 \%-\text { да, } \\
36,4 \%-\text { нет }\end{array}$ & $\begin{array}{l}88,8 \%-\text { да, } \\
11,2 \%-\text { нет }\end{array}$ & $\begin{array}{l}54,4 \%-д а, \\
45,6 \%-\text { нет }\end{array}$ \\
\hline $\begin{array}{l}\text { Если да, то в какой } \\
\text { форме? }\end{array}$ & $\begin{array}{l}50 \% \text { - игра на музы- } \\
\text { кальном инструменте, } \\
\text { в инструментальных ан- } \\
\text { самблях, оркестрах, } \\
50 \% \text { - занятия музыкой } \\
\text { как средство оздоровле- } \\
\text { ния (техника музыкоте- } \\
\text { рапии) }\end{array}$ & $\begin{array}{l}62,5 \% \text { - индивидуаль- } \\
\text { ные занятия вокалом, } \\
37,5 \% \text { - изучение игры } \\
\text { на музыкальном инст- } \\
\text { рументе в мини- групाе } \\
\text { (с другом (подругой), } \\
\text { родственником, ребен- } \\
\text { ком) }\end{array}$ & $\begin{array}{l}60 \% \text { - пение в хоре, } \\
20 \% \text { - изучение игры } \\
\text { на музыкальном инст- } \\
\text { рументе } \\
\text { в минигруппе (с другом } \\
\text { (подругой), родственни- } \\
\text { ком, ребенком), } \\
20 \% \text { - занятия музы- } \\
\text { кой как средство оздо- } \\
\text { ровления (техника му- } \\
\text { зыкотерапии) }\end{array}$ \\
\hline $\begin{array}{l}\text { Хотели бы Вы научить- } \\
\text { ся играть на музыпаль- } \\
\text { ном инструменте? }\end{array}$ & $\begin{array}{l}60,6 \%-\text { да, } \\
39,4 \%-\text { нет }\end{array}$ & $\begin{array}{l}88,8 \%-\text { да, } \\
11,2 \%-\text { нет }\end{array}$ & $\begin{array}{l}36 \%-\text { да, } \\
64 \%-\text { нет }\end{array}$ \\
\hline $\begin{array}{l}\text { Если да, то с какой } \\
\text { целью? }\end{array}$ & $\begin{array}{l}55 \text { \% - для получения } \\
\text { дополпительного навы- } \\
\text { ка, в целях саморазви- } \\
\text { тия, самообразования, } \\
25 \% \text { - для того, чтобы } \\
\text { научиться играть любые, } \\
\text { популярные мелодии, } \\
20 \text { \% - для музицирова- } \\
\text { ния на фортепиано как } \\
\text { средства расслабления, } \\
\text { восстановления эмо- } \\
\text { ционального состояния }\end{array}$ & $\begin{array}{l}87,5 \% \text { - получать эсте- } \\
\text { тическое удовольствие } \\
\text { от собственного музи- } \\
\text { цирования, } \\
12,5 \% \text { - для музициро- } \\
\text { вания на фортепиано как } \\
\text { средства расслабления, } \\
\text { восстановления эмо- } \\
\text { ционального состояния }\end{array}$ & $\begin{array}{l}75 \% \text { - для того, чтобы } \\
\text { научиться играть любые, } \\
\text { популярные мелодии, } \\
14 \% \text { - получать эсте- } \\
\text { тическое удовольствие } \\
\text { от собственного музи- } \\
\text { цирования, } \\
11 \% \text { - выступать на } \\
\text { эстраде }\end{array}$ \\
\hline
\end{tabular}

Показатели выбора инструментального исполнительства в качестве вида творчества немного ниже, так как данная форма наиболее трудна и требует повышенного внимания. Необходимо отметить интерес первой группы к использованию музыкальнотерапевтических практик как средства расслабления, восстановления эмоционального состояния. Мы предполагаем, что подобный ответа вызван современной проблемой эмоционального выгорания людей, работающих в системе «человек - человек», какими являлись респонденты данной группы (педагоги, бухгалтера, врачи), а также студентымагистры Казанского национального исследовательского технологического университета, большинство из которых совмещает учебу и работу.

Таким образом, опираясь на результаты проведенного анкетирования и возможности организации занятий активными формами творчества в музейном пространстве, мы выбрали в качестве формы творчества инструментальное музицирование на фортепиано, так как данное направление в той или иной степени актуально для каждой группы. Для подтверждения эффективности приема музицирования, особенно для лиц пожилого возраста, для которых игра на фортепиано используется в качестве профилактики болезни Альцгеймера, мы опирались на исследование П. Джаната о существовании тесных связей музыки и воспоминаний, называемых им «мозговые подписи» [цит. по 7]. В ходе исследования им установлено, что во время прослушивания испытуемыми музыки, которая была популярна в их юности, в 50 \% случаев они подробно описывали воспоминания, что доказывало, какими яркими они были. Выбор применения метода музицирования в качестве оздоровительного обусловлен доказанным фактом о том, что необходимость 
сложной координации обеих рук при игре на клавишных требует роста в той области мозга, которая обеспечивает обмен информацией между руками. Это подтверждается тем, что у некоторых профессиональных музыкантов мозолистое тело мозга не только больше, но и работает иначе: у них передача всех видов информации (включая зрительную) между полушариями происходит быстрее, чем у немузыкантов. Необходимо отметить, что человеческий мозг обладает уникальным свойством - пластичностью, то есть способностью реорганизовать проводящие пути и синапсы в соответствии с внешними условиями и биологическими потребностями. Эта способность объясняет длительное существование человека как биологического вида. Благодаря этому никогда не поздно учиться, например, музыке, поскольку обучение игре на инструменте или пению - способ стимуляции умственной деятельности.

Таким образом, целью занятий на инструменте для всех групп было научиться играть и разбирать любимые мелодии, а также демонстрировать их на публике. Нашей задачей было найти те приемы музыкального обучения, которые способствовали бы более быстрому овладению музыкальной грамотой и при этом не доставляли сильного напряжения для участников. Обучение музыкальному ритму мы начинали с выполнения ритмической гимнастики по методу Ж. Далькроза [см. 8] (изучение ритма 2/4, 3/4, 4/4 с помощью движений); расположение нот на клавиатуре осваивали в форме игры (данный прием подразумевает нахождение вслепую нот «ре» (находящиеся между двумя черными клавишами), «фа» (перед тремя черными) и «си» (после трех черных), далее - остальных: 〈ми», «(соль», «Ля), «до». Работа с закрытыми глазами способствовала развитию контакта с клавиатурой и активизации слуха, что ускоряет процесс овладения музыкальной грамотой и применения ее на практике в виде подбора и разбора любимых мелодий.

В работе с группами по музицированию на фортепиано использовались индивидуальные и ансамблевые формы занятий. Последние способствовали не только удовлетворению потребности в проведении совместного досуга (например, девушкой и юношей, двумя подругами пожилого возраста, матерью и сыном), но и развитию коммуникативных навыков, проявляющихся в умении сотрудничать друг с другом. Результатом деятельности группы является выступление ее членов в музыкально-образовательных программах (лекториях) автора, проводимых в галереях, музеях г. Казани.

Резюме. Анализ российского и зарубежного опыта организации рекреационнооздоровительных программ в музейном пространстве способствовал определению главного принципа организации нашей работы по применению рекреационнооздоровительных практик - создание неформальной, доброжелательной атмосферы, способствующей погружению человека в творческую деятельность, которая способствовала бы не только удовлетворению потребностей в отдыхе и развлечении, но и духовному развитию личности.

Применение метода театральной деятельности с детской и подростковой группой, основанной на принципе сотворчества, помогало в привлечении в мир искусства личности, не имеющей опыта занятий активными творческими практиками. Кроме того, следуя рекомендациям специалистов в области раскрытия целительного потенциала искусства, можно рассматривать метод театральной деятельности с позиции корректирующего вспомогательного приема повышения социального здоровья детей и подростков.

Использование со всеми участниками музыкально-образовательных программ (лекториев) импрессивного метода музыкотерапии в форме творческой медитации, осуществляемой в середине мероприятия, способствовало отдыху, снятию напряжения у аудитории, а также развитию ведущих компонентов творчества - воображения (посредством изображения образов на бумаге), мотивации (проявлялась в доработке творческих работ для выставки в Детской студии-галерее им. И. К. Зарипова). 
Применение приема инструментального музицирования на фортепиано, по нашему мнению, оказывает сильное воздействие на развитие творчества и оздоровление личности. В процессе подбора приемов работы, форм организации деятельности мы учитывали возрастные особенности, интересы и потребности группы. Считаем, что успех реализации данного приема с людьми старше 18 лет обусловлен подбором универсальных приемов (например, знакомство с ритмом с помощью ритмической гимнастики и т. Д.), помогающих в форме игры преодолеть главные трудности инструментального искусства (овладение музыкальной грамотой и приемами игры и пр.), а таюже доставляющих удовольствие от процесса, в котором они участвуют.

Таким образом, применение перечисленных приемов и методов, основанных на целительной природе музыкального искусства, доказывает актуальность и необходимость осуществления рекреационно-оздоровительных практик в культурно-досуговом учреждении (музее), обладающем уникальной способностью погружать человека в мир искусства

\section{ЛИТЕРАТУРА}

1. Баранова С. В. Настроение здоровья. - М. : Единение, 2008. - 176 c.

2. Загорская Л. М., Назаркина В. А. Альтернативные культурно-досуговые технологии. - Новосибирск : Изд-во НГТУ, 2017. - 152 с.

3. Киселева Т. Г., Красильников Ю. Д. Социально-культурная деятельность : учебник. - М. : МГУКИ, 2004. $-539 \mathrm{c}$.

4. Петруиии В. И. Музыкальная психология : учебник и практикум для академического бакалавриата. - М. : Юрайт, 2017. -380 с.

5. Праслова Г. А. Инструментальное музицирование как средство активной музыкотерапии // Музыкотерапия сегодня: наука, практика, образование : сборник докладов и тезисов Международной конференщии [Электронный ресурс]. - Режим доступа : http://drevoroda.ru/assets/files/pdf/sbornik_konferen_mt_2019.pdf.

6. Сиротюк A. Л. Синдром дефицита внимания с гиперактивностью. Диагностика, коррекция и практические рекомендации родитепям и педагогам. - М. : Сфера, 2002. - 128 с

7. Уильямсон B. Мы - это музыка. Как музыка влияет на наш мозг, здоровье и жизњь в целом. - М. : Манн, Иванов и Фербер, 2016. -162 с.

8. Указ Президента Российской Федерации от 29.05.2017 № 240 «Об объявлении в Российской Федерации „Десятилетия детства"» [Электроншй ресурс]. - Режим доступа : https://rg.ru/2017/05/29/prezidentukaz240-site-dok.html.

9. Хамель П. М. Через музыку к себе. Как мы познаем и воспринимаем музыку. - М. : Классика-XXI, 2017. $-248 \mathrm{c}$.

10. Шуиарджан C. В. Современные методы музыкальной терапии и эффекты, возникаюшие при воздействии музыкой и различпыми акустическими сигналами на организм человека // Традищионная медицина. Восток и Запад. - 2005. - Т. 2, № 2. - С. 23-29.

11. Bejan A. The development of creativity through theatrical techniques. - URL http://rae.arts.ro/files/9514/5915/3921/RAE_7-82014.pdf.

12. Ioannides $E$. Art therapy in museums. - URL : https://www.museeum.com/art-therapy-in-museums

13. Why Museums Don't Suck: The Current State of Teen Engagement. - URL : https://artmuseumteaching.com/2012/10/28/why-museums-dont-suck.

Статья поступила в редакцию 03.12.2019

\section{REFERENCES}

1. Baranova $S$. $V$. Nastroenie zdorov'ya. - M. : Edinenie, 2008. $-176 \mathrm{~s}$.

2. Zagorskaya L. M., Nazarkina V. A. Al'ternativnye kul'turno-dosugovye tekhnologii. - Novosibirsk : Izd-vo NGTU, 2017. - $152 \mathrm{~s}$ $539 \mathrm{~s}$.

3. Kiseleva T. G., Krasil'nikov Yu. D. Social'no-kul'turnaya deyatel'nost' : uchebnik. - M. : MGUKI, 2004. -

4. Petrushin V. I. Muzykal'naya psihologiya : uchebnik i praktikum dlya akademicheskogo bakalavriata. M. : Yurajt, 2017. $-380 \mathrm{~s}$. 
5. Praslova G. A. Instrumental'noe muzicirovanie kak sredstvo aktivnoj muzykoterapii // Muzykoterapiya segodnya: nauka, praktika, obrazovanie : sbornik dokladov i tezisov Mezhdunarodnoj konferencii [Elektronnyj resurs]. - Rezhim dostupa : http://drevoroda.ru/assets/files/pdf/sbornik_konferen_mt_2019.pdf.

6. Sirotyuk A. L. Sindrom deficita vnimaniya s giperaktivnost'yu. Diagnostika, korrekciya i prakticheskie rekomendacii roditelyam i pedagogam. - M. : Sfera, 2002. - $128 \mathrm{~s}$.

7. Uil'yamson V. My - eto muzyka. Kak muzyka vliyaet na nash mozg, zdorov'e i zhizn' v celom. - M. : Mann, Ivanov i Ferber, 2016. -162 s.

8. Ukaz Prezidenta Rossijskoj Federacii ot 29.05.2017 № 240 «Ob ob"yavlenii v Rossijskoj Federacii „Desyatiletiya detstva"» [Elektronnyj resurs]. - Rezhim dostupa : https://rg.ru/2017/05/29/prezident-ukaz240-sitedok.html.

9. Hamel' P. M. Cherez muzyku k sebe. Kak my poznaem i vosprinimaem muzyku. - M. : Klassika-XXI, 2017. $-248 \mathrm{~s}$.

10. Shushardzhan $S$. V. Sovremennye metody muzykal'noj terapii i effekty, voznikayushchie pri vozdejstvii muzykoj i razlichnymi akusticheskimi signalami na organizm cheloveka // Tradicionnaya medicina. Vostok i Zapad. - 2005. - T. 2, № 2. - S. 23-29.

11. Bejan A. The development of creativity through theatrical techniques. - URL http://rae.arts.ro/files/9514/5915/3921/RAE_7-82014.pdf.

12. Ioannides $E$. Art therapy in museums. - URL : https://www.museeum.com/art-therapy-in-museums.

13. Why Museums Don't Suck: The Current State of Teen Engagement. - URL : https://artmuseumteaching.com/2012/10/28/why-museums-dont-suck.

The article was contributed on December 03, 2019

\section{Сведения об авторе}

Камалова Гульнур Рафисовна - преподаватель кафедры музыкальноинструментального исполнительства Казанского государственного института культуры, г. Казань, Россия; e-mail: gulnurrk88@mail.ru

\section{Author information}

Kamalova, Gulnur Rafisovna - Lecturer, Department of Music Instrumental Performance, Kazan State Institute of Culture, Kazan, Russia; e-mail: gulnurrk88@mail.ru 